\title{
Titreşim takozunun giyotin makas tezgâhında, titreşim yalıtımına etkisinin araştırılması
}

\author{
Abdurrahman KARABULUT ${ }^{\mathrm{a}}$ (D), Ahmet KÖKEN*,b \\ ${ }^{a}$ Afyon Kocatepe Üniversitesi Makine Mühendisliği Bölümü, 03100, AFYONKARAHISAR, TÜRKIYE

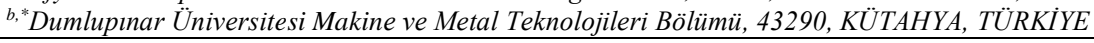

\begin{tabular}{|c|c|}
\hline $\begin{array}{l}\text { MAKALE } \\
\text { BÍLGISİ }\end{array}$ & $\ddot{O ̈ Z}$ \\
\hline $\begin{array}{l}\text { Alınma: } 10.02 .2020 \\
\text { Kabul: } 13.10 .2020\end{array}$ & $\begin{array}{l}\text { Bu çalışmada, giyotin makasın titreşim yalıtımını sağlamak için elastomer titreşim takozlarının } \\
\text { tezgâh titreşim yalıtımına etkisi araştırılmıştır. Bu amaçla, ilk önce, giyotin makasın gövdesinde }\end{array}$ \\
\hline $\begin{array}{l}\text { Anahtar Kelimeler: } \\
\text { Giyotin makas, } \\
\text { Titreşim takozu, } \\
\text { Sönümleme, } \\
\text { Tezgâh zemin yalıtımı }\end{array}$ & $\begin{array}{l}\text { ve zemindeki titreşim büyüklükleri deneysel yollarla belirlenmiştir. Daha sonra, tezgâh ağırlığına } \\
\text { ve kapasitesine göre seçilen dört adet titreşim takozu tezgâh ayaklarına yerleştirilmiştir. Titreşim } \\
\text { takozunun tezgâh gövdesindeki ve zemine geçen titreşime etkisi incelenmiştir. Tezgâhın ve } \\
\text { zeminin titreşim değerleri dört kanallı ivme ölçerle eş zamanlı olarak ölçülmüştür. Titreşim } \\
\text { takozlu ve titreşim takozsuz yapılan ölçüm sonuçları arasındaki farklar grafikler üzerinde } \\
\text { gösterilmiştir. Sonuç olarak, giyotin makasın zemin bağlantısında titreşim takozu kullanılması } \\
\text { hem tezgâh gövdesindeki hem de zemine geçen titreşimi azalttığı görülmüştür. }\end{array}$ \\
\hline $\begin{array}{l}\text { Sorumlu Yazar: } \\
\text { e-posta: } \\
\text { ahmet.koken@ dpu.edu } \\
\text {.tr }\end{array}$ & https://dx.doi.org/10.30855/gmbd.2020.03.04 \\
\hline $\begin{array}{l}\text { Investigation } \\
\text { isolation of } \mathrm{t}\end{array}$ & $\begin{array}{l}\text { the effect of the vibration wedge on the vibration } \\
\text { illotine shears machine }\end{array}$ \\
\hline
\end{tabular}

\section{ARTICLE}

INFO

Received: 10.02 .2020

Accepted: 13.10 .2020

\section{Keywords:}

Guillotine shears,

Vibration wedge,

Damping,

Workbench ground

insulation

\section{"Corresponding}

Authors

ahmet.koken@dpu.edu.t

\begin{abstract}
In this study, the effect of elastomer vibration wedges on workbench vibration isolation was investigated to provide vibration isolation of guillotine shears. For this purpose, first, vibration magnitudes on the body and the ground of the guillotine shear were determined experimentally. Then, four vibration wedges selected according to the weight and capacity of the machine were placed under the workbench legs. The effect of the vibration wedge on the vibration on the body of the machine and on the floor was examined. The vibration values of the workbench and the floor were measured simultaneously with a four-channel accelerometer. The differences between the measurement results made with and without vibration wedges are shown on the graphs. As a result, it has been observed that by using vibration wedge in the ground connection of the guillotine shears, it reduces the vibration both in the workbench body and the ground.
\end{abstract}

https://dx.doi.org/10.30855/gmbd.2020.03.04

\section{GÍRISS (INTRODUCTION)}

Titreşime maruz yapı ya da makine bileşeni uygulanan kuvvetlerin sürekli çevrimsel Bu makaleye atıf yapmak için: A. Karabulut ve A. Köken, "Titreşim takozunun giyotin makas tezgâhında, titreşim yalıtımına etkisinin araştırılması," Gazi Mühendislik Bilimleri Dergisi, cilt 6, sayı 3, s. 210-216, Aralık, 2020, doi: https://dx.doi.org/10.30855/gmbd.2020.03.04.

değişiminden kaynaklanan malzeme yorulması dolayısıyla malzemede hasara yol açmaktadır. İlaveten yatak ve dişli gibi makine elemanlarının daha çabuk aşınmasına yol açar ve de aşırı gürültüye 
neden olur. Makinelerde titreşim cıvata bağlantılarını gevşetebilir [1]. Tezgâhta oluşan titreşimleri azaltabilmek için titreşim sönümleyicilerin etkili olduğu belirtilmiştir [2-4]. Araştırmacıların kesme işlemleri esnasında meydana gelen titreşimleri azaltmak için geliştirdikleri sistemlerin, oluşan titreşim ivme seviyelerinde önemli miktarda azalmaya neden olduğu görülmüştür [5]. Makinelerin dinamik davranışlarını kontrol etmek için izolasyon sistemleri ve titreşim izolasyon yöntemleri geliştirilmiştir. Titreşim yalıtımında genellikle metal yay, kauçuk, esnek yastık ve benzeri malzemeler kullanılır [6]. Titreşim izolasyon sistemleri makinenin kullanılacağı amaç doğrultusunda, pasif, yarı aktif ve aktif izolasyon sistemleri olarak dizayn edilmektedir [7-10].

Her ne zaman makine ya da yapının doğal titreşim frekansı dış zorlanma frekansı ile çakışırsa, orada rezonans olarak bilinen bir olay ortaya çıar. Rezonans ise aşırı yer değiştirme ve hasara yol açar [1]. $\mathrm{Bu}$ gibi durumlarda sistemin dinamik analizlerinin, teorik ve deneysel olarak yapılması ve gerekli önlemlerin alınması gerekmektedir [11].

Giyotin makas endüstride geniş bir alanda kullanılmaktadır. Kullanım kolaylığı ve kaliteli imalat yapabilmek için tezgâhın titreşimsiz şekilde çalışması gerekmektedir. İmalatta maliyeti etkiyen bir çok faktör vardır. Bu faktörler içerisinde en önemlilerinden bir tanesi takım ömrüdür. Takım ömrünün ise en çok etkilendiği etkenlerden biri ise titreşimdir. Kontrolsüz olarak oluşan bu titreşimler, iş parçası yüzey kalitesi, kesici takım aşınması ve işleme performansına olumsuz etki etmektedir [1216]. İstenmeyen titreşim ve gürültünün operatöre, tezgâha, takıma ve üretilen iş parçasına zarar vermemesi için tezgâhın uygun bir titreşim izolasyon sistemine sahip olması gerekir. Giyotin makasın gövdesi makine destek sistemi üzerinde hareket eder. Bir makine yatağı ve zemin arasındaki titreşim karakteristiklerinin titreşim üzerinde büyük etkisi vardır. Bu nedenle, titreşimin genliğini azaltmak için destek sisteminin sönümlemesi önemlidir [17].

Titreşim sönümleyicilerin gerek tasarımı gerekse de titeşim yalıtımları üzerine birçok çalışma mevcuttur. Küçükrendeci [6] endüstriyel uygulamalar için alüminyum-kauçuk sadviç tip mekanik titreşim yalıtım elemanının tasarımını yapmıştır. Ardıç [18] hassas donanımların titreşim yalıtımını sağlamak için kullanılacak elostomer titreşim takozlarının tasarımı için bir süreç geliştirmiştir. Mori ve arkadaşları [19] takım tezgâhlarındaki titreşimini azaltmak için viskoelastik titreşim takozu modeli geliştirmişlerdir. Önerilen modele göre, titreşim takozunun sönüm alanını ayarlamadan titreşimi azaltmak için çeşitli takım tezgâhlarında kullanılabileceği belirtilmiştir. Eken [20] üretim tezgâhlarının zemin titreşimi ve yalıtımı üzerine yaptığı çalışmada, tezgâh ayaklarında kullanılan titreşim sönümleyicinin zemine geçen titreşim genliğini azaltıcı yönde bir etki yaptığ belirtilmiştir.

$\mathrm{Bu}$ çalışmada, giyotin makasın titreşim yalıtımında titreşim takozunun etkileri incelenmiş, bunun için piyasada yaygın olarak kullanılan mekanik titreşim takozları kullanılmıştır. Giyotin makasın kesme esnasında oluşan kuvvet sonucu zemine geçen titreşim ile tezgâh gövdesindeki titreşimlerin büyüklüğü ölçülmüştür. Titreşim parametrelerinden yer değiştirme, hız ve ivme büyüklükleri ölçülerek, titreşim takozunun giyotin makasın titreşim yalıtımına etkisi incelenmiştir.

\section{MATERYAL VE DENEYSEL KURULUM (MATERIAL AND EXPERIMENTAL SETUP)}

\subsection{Tezgâh ve Yalıtım Malzemeleri (Workbench and Insulation Materials)}

Deneysel çalışmada kullanılan giyotin makas yaklaşık 2 ton ağırlığında ve 1260 x $2.5 \mathrm{~mm}$ sac kesim kapasitesine sahiptir. Şekil 1'de titreşim takozunun giyotin makas tezgâhının ayakları altına yerleştirilmesi görülmektedir. Yalıtım elemanı olarak kullanılan titreşim takozunun taşıma kapasitesi $10000 \mathrm{~N}$ ve elastomer malzemeden yapılmıştır. Tezgâh ağırlığına ve kapasitesine göre seçilen titreşim takozunun boyutları Tablo 1'de verilmiştir. 


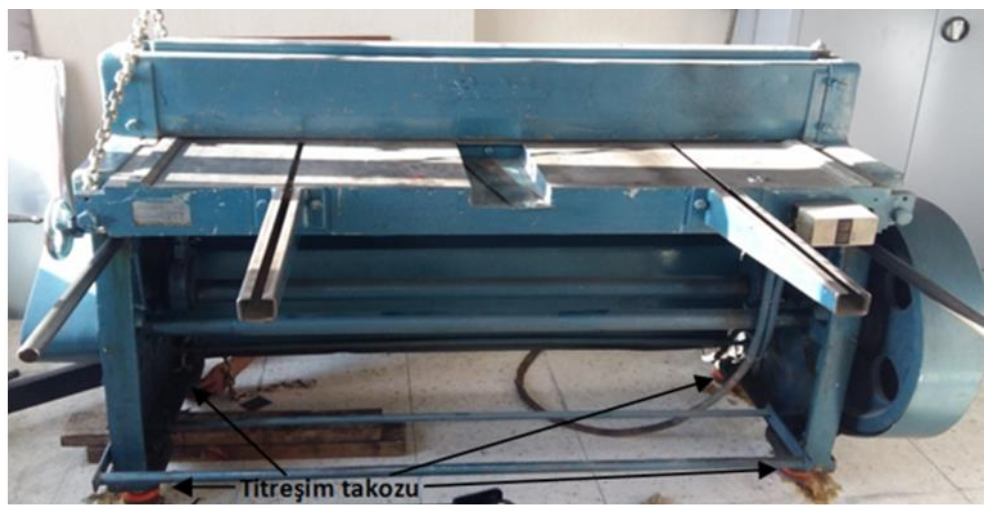

Şekil 1. Titreşim takozunun yerleştirilmesi (Installing the vibration wedge)

Tablo 1. Titreşim takozu boyutları (Vibration wedge dimensions) ( $\mathrm{mm}$ )

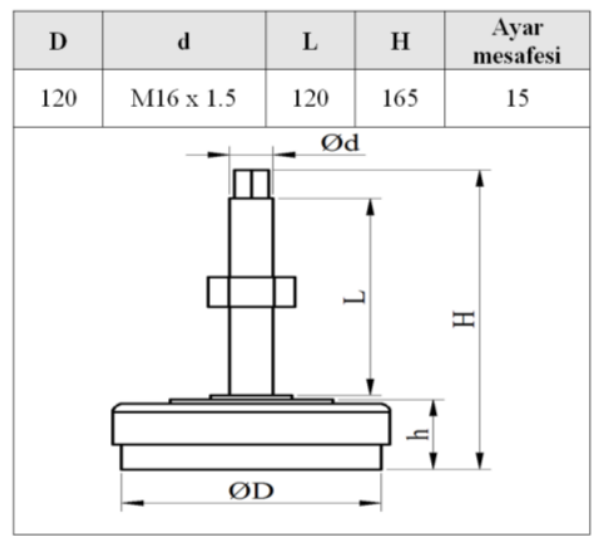

\subsection{Titreșim Ölçümü (Vibration Measurement)}

Titreşim ölçümü Tablo 2'de teknik özellikleri verilen VB500 - dört kanallı titreşim ölçüm ve kayıt cihazıyla yapılmıştır. Titreşim ölçümü yapılırken zemin ve tezgâh üzerindeki üç nokta dikkate alınmış; zemin $(\mathrm{CH} 1)$, tezgâh ayağ1 $(\mathrm{CH} 2)$, kesici takımın olduğu nokta $(\mathrm{CH} 3)$ ve tezgâhın tepe noktasına $(\mathrm{CH} 4)$ sensörler yerleştirilmiştir. Algılayan sensör çok hassas olduğundan zemin bağlantısının sağlam bir noktadan yapılması gerekir. Zemin titreşimini ölçmek için zemin üzerine metal malzeme sabitlenerek, sensör zemindeki metal malzeme üzerine tutturulmuştur. Datalogger cihazı ile titreşim ölçümü ve ivmeölçer sensörlerinin tezgâh üzerindeki konumlarını gösteren deneysel kurulum Şekil 2'de görülmektedir. Tezgâhın titreşim hareketi $2 \mathrm{~mm}$ kalınlığında ve $1000 \mathrm{~mm}$ uzunluğundaki St 37 malzemeden siyah sac levha kesilirken bütün noktalardan eş zamanlı olarak titreşim değerleri ölçülmüştür. İvmelenme sensöründen çıkan sinyaller cihazda bulunan bir SD karta excel formatında kaydedilmiştir. Veri kartına kaydedilen titreşim verileri bilgisayar ortamına aktarılarak grafiklere dönüştürülmüştür.

Tablo 2. İvme ölçerin teknik özellikleri (Technical properties of the accelerometer)

\begin{tabular}{|c|c|c|c|}
\hline \multirow[t]{5}{*}{ İvme } & Ölçüm aralığı & Çözünürlük & Hassasiyet \\
\hline & $0.5 \ldots 199 \mathrm{~m} / \mathrm{s}^{2}$ & $0.1 \mathrm{~m} / \mathrm{s}^{2}$ & \multirow{3}{*}{$\begin{array}{l} \pm(5 \%+2 \text { digits }) \\
80-160 \mathrm{~Hz}\end{array}$} \\
\hline & $0.05 \ldots 20.39 \mathrm{G}$ & $0.01 \mathrm{~g}$ & \\
\hline & $2 \ldots 656 \mathrm{ft} / \mathrm{s}^{2}$ & $1 \mathrm{ft} / \mathrm{s}^{2}$ & \\
\hline & \multicolumn{3}{|c|}{ Kalibrasyon noktas1 : $50 \mathrm{~m} / \mathrm{s}^{2}-160 \mathrm{~Hz}$} \\
\hline \multirow[t]{4}{*}{ Hiz } & $0.5 \ldots 199.9 \mathrm{~mm} / \mathrm{s}$ & $0.1 \mathrm{~mm} / \mathrm{s}$ & \multirow{3}{*}{$\begin{array}{l} \pm(5 \%+2 \text { digits }) \\
80-160 \mathrm{~Hz}\end{array}$} \\
\hline & $0.05 \ldots 19.99 \mathrm{~cm} / \mathrm{s}$ & $0.01 \mathrm{~cm} / \mathrm{s}$ & \\
\hline & $0.02 \ldots 7.87 \mathrm{in} / \mathrm{s}$ & $0.01 \mathrm{in} / \mathrm{s}$ & \\
\hline & \multicolumn{3}{|c|}{ Kalibrasyon noktas $1: 50 \mathrm{~mm} / \mathrm{s}, 160 \mathrm{~Hz}$} \\
\hline \multirow[t]{3}{*}{ Yer değiştirme } & $0.003 \ldots 1.999 \mathrm{~mm}$ & $0.001 \mathrm{~mm}$ & \multirow{2}{*}{$\begin{array}{l} \pm(5 \%+2 \text { digits }) \\
80-160 \mathrm{~Hz}\end{array}$} \\
\hline & $0.078 \mathrm{in}$ & $0.001 \mathrm{in}$ & \\
\hline & \multicolumn{3}{|c|}{ Kalibrasyon noktası : $0.141 \mathrm{~mm}, 160 \mathrm{~Hz}$} \\
\hline Frekans aralığ & \multicolumn{3}{|l|}{$10 \mathrm{~Hz} \ldots 1 \mathrm{kHz}$} \\
\hline Tepkime süresi & \multicolumn{3}{|l|}{ Yaklaşık 1 saniye } \\
\hline Hafıza & \multicolumn{3}{|l|}{$1-16 \mathrm{~GB}$} \\
\hline Veri kayıt aralığ & \multicolumn{3}{|c|}{$1-3600$ saniye aralığında } \\
\hline Çalıșma şartları & \multicolumn{3}{|c|}{$0 \ldots 50^{\circ} \mathrm{C},<85 \% \mathrm{RH}$ (yoğuşması) } \\
\hline Pil & \multicolumn{3}{|c|}{$8 \times$ AA veya $9 \mathrm{~V}$ AC adaptör } \\
\hline Ebatlar & \multicolumn{3}{|c|}{ Cihaz : 203x76x38mm, Prob: 16mm (çap), 37mm (uzunluk) } \\
\hline Ağırlık & \multicolumn{3}{|c|}{ ( } \\
\hline
\end{tabular}




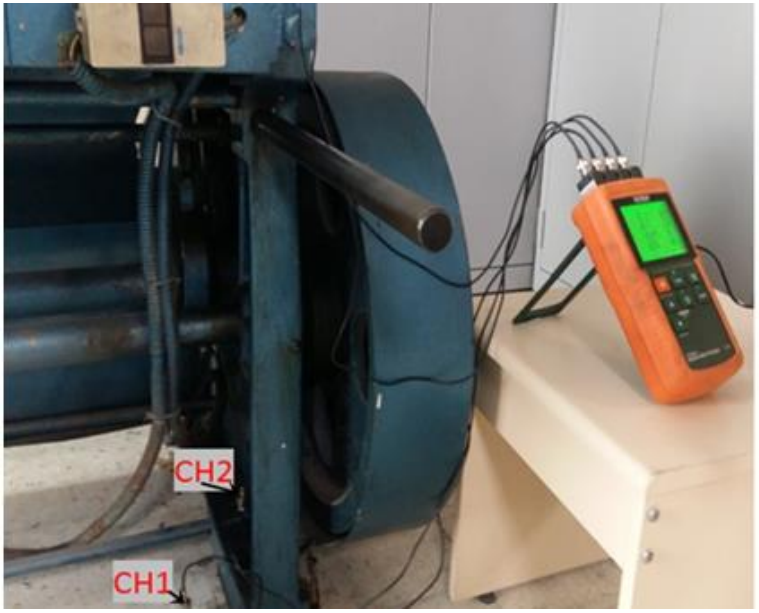

a) $\mathrm{H} 1$ ve $\mathrm{CH} 2$ sensörleri ( $\mathrm{CH} 1$ and $\mathrm{CH} 2$ sensors)

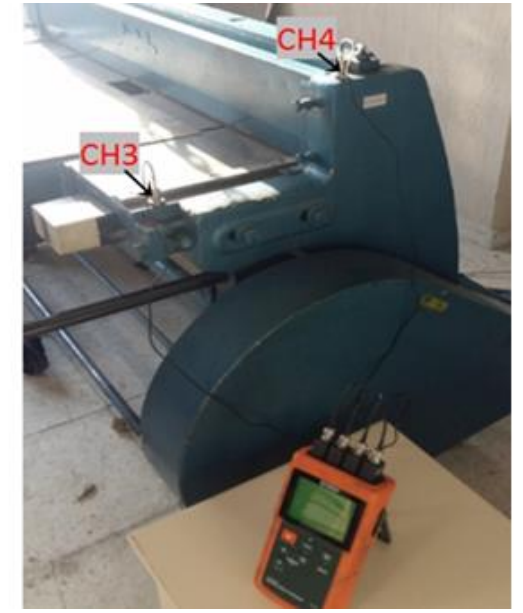

b) $\mathrm{CH} 3$ ve $\mathrm{CH} 4$ sensörleri ( $\mathrm{CH} 3$ and $\mathrm{CH} 4$ sensors)

Şekil 2. Deneysel kurulum (Experimental setup)

\section{SONUÇLAR VE TARTIŞMA (RESULTS AND DISCUSSION)}

Dört kanallı ivme ölçerle yer değiştirme, hız ve ivme büyüklükleri ölçülmüştür. Titreşim takozlu ve titreşim takozsuz yapılan ölçüm sonuçları arasındaki farklar grafikler üzerinde gösterilmiştir. Bu değerlere göre tezgâhın yalıtımlı ve yalıtımsız durumu karşılaştırılmıştır.

\subsection{Yer Değiştirme Değerleri (Displacement Values)}

Tezgâh ayağ1 (CH2) ve kesme düzlemindeki (CH3) sensörlerle yer değiştirme değerleri belirlenmiştir (Şekil 3). Grafiklerde yalıtımlı ve yalıtımsız ölçülen titreşim yer değiştirme değerleri karşılaştırmalı olarak verilmiştir. Yalıtımlı ve yalıtımsız durumda tezgâhta aynı şartlarda kesim yapılmış, ama zemin ve tezgâhtaki titreşim değerlerinin farklı olduğu görülmüştür. Yalıtımsız ölçümde tezgâh ayağında yer değiştirme pik değeri yaklaşık $1.6 \mathrm{~mm}$ ve kesme düzleminde yaklaşık $1 \mathrm{~mm}$ ölçülen titreşimi takoz sönümleyerek azaltmıştır. Tezgâh üzerindeki ivme alıcıların bağlandığı noktalardan bakıldığında, tezgâh ayağının yer değiştirme değerlerinin her ikisinin de birbirine yakın olduğu, diğer noktalarda yalıtımsız olanın daha yüksek olduğu görülmüştür. Yalıtım sonucunda, tezgâhtaki ve zemine iletilen titreşim büyük oranda düşmüştür. Eken, 2017’ de yapmış olduğu çalışmada benzer sonuçlar elde etmiştir.

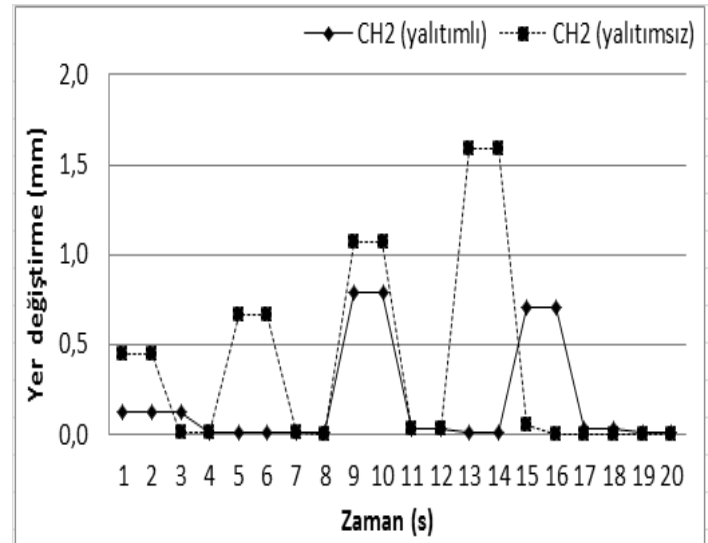

a) Tezgâh ayağı yer değiştirme değerleri (Workbench foot displacement values)

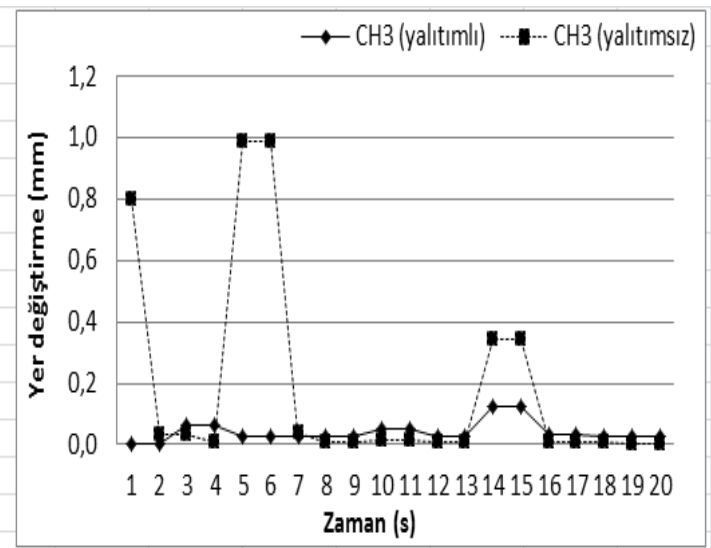

b) Kesme düzlemi yer değiştirme değerleri (Cutting plane displacement values)

Şekil 3. Yer değiştirme değerlerinin karşılaştırılması (Comparison of displacement values) 


\subsection{Hız Değerleri (Velocity Values)}

Şekil 4' de zemin (CH1) ve kesme düzlemindeki (CH3) sensörlerle ölçülen hız değerleri verilmiştir. Yalıtımlı ve yalıtımsız yapılan ölçüm sonuçları arasındaki farklar grafikler üzerinde gösterilmiştir. Grafikler incelendiğinde, kesme düzleminde pik değeri yaklaşık $60 \mathrm{~mm} / \mathrm{s}$ ölçülen titreşim hız değeri, titreşim takozu sayesinde yaklaşı $10 \mathrm{~mm} / \mathrm{s}$ seviyelerine düştüğü görülmüştür. Titreşim takozu

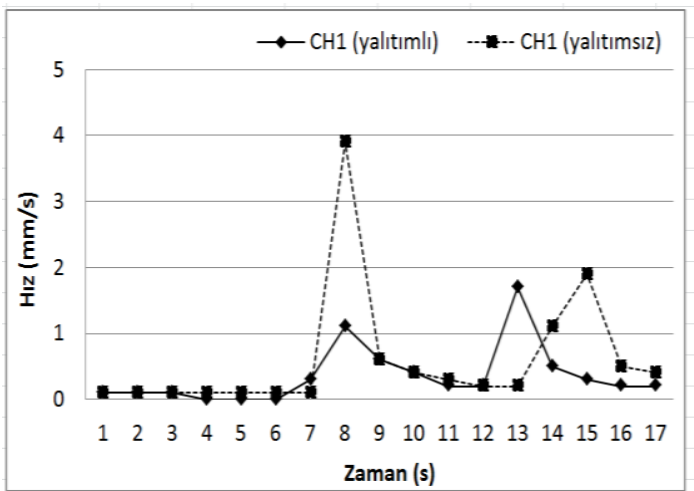

a) Zemin hız değerleri (Ground velocity values) tezgâh ayağındaki ve kesme düzlemindeki titreşimi sönümleyerek azaltmıștır. Hız değerlerinin tezgâh gövdesindeki üst noktalara doğru yükseldiği, zemine yakın yerlerde hız değerlerinin düşük olduğu görülmüştür. Yalıtım malzemesi sayesinde, tezgâhın gövdesindeki hız değerleri yalıtımsız değerlerden aşağıda kalmıştır.

Şekil 4. H1z değerlerinin karşılaştırılması (Comparison of velocity values)

\section{3. İvme Değerleri (Acceleration Values)}

Tezgâh ayakları altına titreşim takozu yerleştirmeden ayakların direkt zemine temasından alınan ölçüm değerleri ve titreşim takozu yerleştirilerek ölçülen ivme değerleri belirlenmiştir. Zemin (CH1) ve kesme düzlemindeki (CH3) sensörlerle ivme değerleri değişimi ölçülmüştür (Şekil 5). Grafiklere bakıldığında, yalıtımsız ölçümde tezgâh ayağında ve gövde üzerinde ölçülen ivme değerlerinin

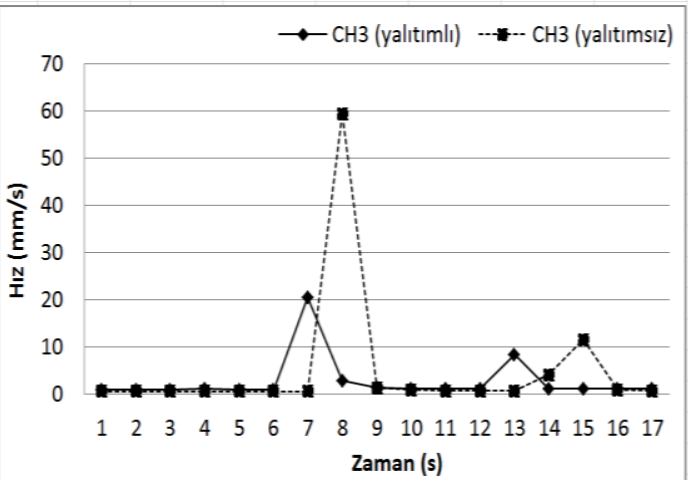

b) Kesme düzlemi hız değerleri (Cutting plane velocity values)

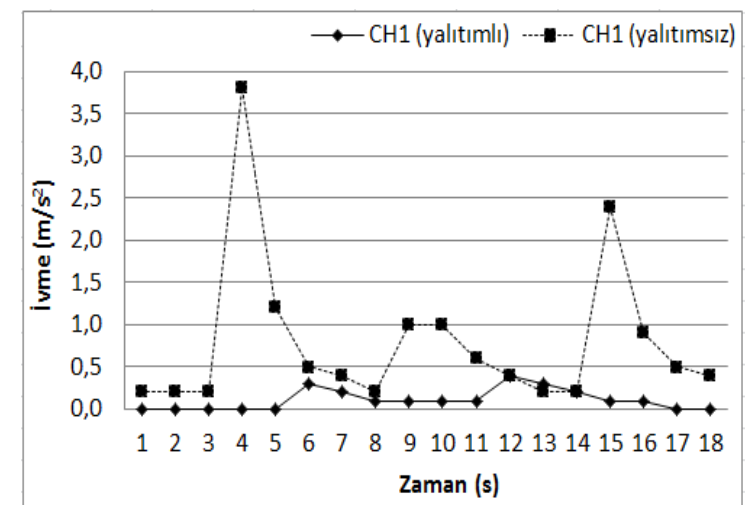

a) Zemin ivme değerleri (Ground acceleration values) arttığı görülmüştür. Yalıtımsız yapılan titreşim ölçümünde zemine geçen titreşim ivme pik değeri yaklaşık $3.8 \mathrm{~m} / \mathrm{s}^{2}$ iken, titreşim takozu sayesinde yaklaşık $0.3 \mathrm{~m} / \mathrm{s}^{2}$ seviyelerine düşmüştür. Tezgâhın gövdesinde oluşan titreşim ivme değerleri ise tezgâhın ayak ve tepe noktasında yüksek değerde ölçülmüştür. Karabulut, 2019' da yapmış olduğu çalışmada benzer sonuçlar elde etmiştir.

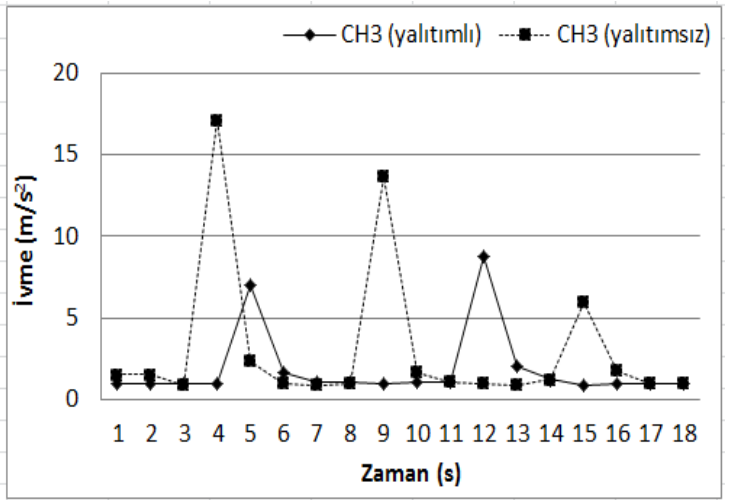

b) Kesme düzlemi ivme değerleri (Cutting plane acceleration values)

Şekil 5. İvme değerlerinin karşılaştırılması (Comparison of acceleration values) 
Yer değiştirme, hız ve ivme grafiklerinden titreşim takozlarının kullanılması, giyotin makasın titreşim değerlerine olumlu yönde etkilemiştir. Titreşim takozlarının doğru seçimi tezgâh gövdesindeki ve zeminde oluşan titreşim değerlerini azalttı̆̆ görülmüştür.

\section{SONUÇLAR (CONCLUSIONS)}

Titreşimli çalışan giyotin makasın titreşim ölçümü yapılmış, bu tezgâh için kullanılacak titreşim takozu tespit edilmiştir. Zeminde ve tezgâhın gövdesindeki salınım hareketini azaltmada titreşim takozunun etkili olduğu görülmüştür. Tezgâh ayaklarında titreşim takozu kullanılması tezgâhın yüksek hassasiyette çalışmasını sağlayacaktır. Titreşimin azaltılmasıyla bina ve tezgâh yıpranması da azalacaktır.

Deneysel çalışmadan elde edilen yer değiştirme, hız ve ivme sonuçları değerlendirildiğinde;

- Giyotin makasın ayaklarına yerleştirilen titreşim takozları sayesinde titreşimin büyüklüğünü azaltmak ve titreşimin zararlarını minimize etmek mümkündür.

- Yer değiştirme, hız ve ivme sonuçlarına bakıldığında; hem zeminde hem de tezgâh gövdesinde yalıtımsız değerlerin yalıtımlı değerlerden daha fazla olduğu görülmüştür.

- Titreşim takozu, giyotin makasta oluşan eksenel ve radyal kuvvetleri sönümleyerek bunların zemine iletilmesini engellemiştir.

- Tezgâhın, ses ve salınım büyüklüğü kontrol altına alınarak daha güvenli çalışması sağlanmıştır.

\section{ÇIKAR ÇATIŞMASI BEYANI (CONFLICT OF INTEREST STATEMENT)}

Yazarlar tarafından herhangi bir çıkar çatışması bildirilmemiştir.

\section{KAYNAKLAR (REFERENCES)}

[1] S.S. Rao, Mechanical Vibrations, $5^{\text {th }}$ Edition, vol. 1, Prentice Hall, University of Miami, 2010.

[2] T. Surmann and D. Biermann, "The effect of tool vibrations on the flank surface created by peripheral milling," CIRP Annals-Manufacturing Technology, vol. 57, no.1, pp. 375-378, 2008. doi: https://doi.org/10.1016/j.cirp.2008.03.059

[3] A. Rashid and C. M. Nicolescu, "Design and implementation of tuned viscoelastic dampers for vibration control in milling," International Journal of Machine Tools \& Manufacture, Vol. 48, no. 9, pp. 1036-1053, July $2008 . \quad$ doi: https://doi.org/10.1016/j.ijmachtools.2007.12.013

[4] K. Tatar and P. Gren, "Measurement of milling tool vibrations during cutting during laser vibrometry," International Journal of Machine Tools \& Manufacture, vol. 48, no. 3-4, pp. 380-387, March 2008.

doi:

https://doi.org/10.1016/j.ijmachtools.2007.09.009

[5] A. Devillez and D. Dudzinski, "Tool vibration detection with eddy current sensors in machining process and computation of stability lobes using fuzzy classifiers," Mechanical Systems and Signal Processing, vol. 21, no. 1, pp. 441-456, 2005. doi: https://doi.org/10.1016/j.ymssp.2005.11.007

[6] İ. Küçükrendeci, "Endüstriyel uygulamalar için alternatif mekanik titreşim yalıtım elemanı tasarımı," OHÜ Müh. Bilim. Derg./OHU J. Eng. Sci., vol. 7, no. 2, pp. 929-936, 2018. doi: 10.28948/ngumuh.445395

[7] Y. Taşkın, "Taşıt titreşimlerinin analizi ve konrolü," Doktora Tezi, Yıldız Teknik Üniversitesi, Fen Bilimleri Enstitüsü, İstanbul, Türkiye, 2008.

[8] L. Sun, "Experimental investigation of vibration damper composed of acoustic metamaterials," Applied Acoustics, vol. 119, pp. 101 - 107, April 2017.

doi:

https://doi.org/10.1016/j.apacoust.2016.12.013

[9] H. Yazıcı, “Çok serbestlik dereceli bir yapının titreşimlerinin bulanık mantıkla kontrolü," Yüksek Lisans Tezi, Yıldız Teknik Üniversitesi, Fen Bilimleri Enstitüsü, İstanbul, Türkiye, 2006.

[10] V. Kahya and O. Araz, "Yüksek hızlı demiryolu köprülerinde aşırı titreşimlerin azaltılmasında paralel bağlı ayarlı kütle sönümleyiciler için basit bir tasarım yöntemi," Journal of the Faculty of Engineering and Architecture of Gazi University, vol. 35, no.2, pp. 607618, 2020. doi: 10.17341/gazimmfd.493102

[11] D.D. Gürsoy, "Bir eksantrik presin pasif titreşim kontrolü yöntemleri ile titreşim izolasyonu," Yüksek 
Lisans Tezi, Yıldız Teknik Üniversitesi, Fen Bilimleri Enstitüsü, İstanbul, Türkiye, 2008.

[12] A.H. El-Sinawi and R. Kashani, "Improving surface roughness in turning using optimal control of tool's radial position," Journal of Materials Processing Technology, vol. 167, no.1, pp. 54-61, August 2005.2 doi: https://doi.org/10.1016/j.jmatprotec.2004.09.079

[13] H. Dilipak and V. Yılmaz, "AISI 1050 çeliğinin karbür takımlarla frezelenmesinde oluşan titreşimlerin incelenmesi ve istatistiksel analizi," Journal of the Faculty of Engineering and Architecture of Gazi University, vol. 27, no. 2, pp. 285-294, Mart 2012.

[14] E. Özcan, “CNC tezgahlarda kullanılan kesici takımlarda takım aşınmasının kesme performansına dinamik etkileri," Doktora Tezi, Marmara Üniversitesi, Fen Bilimleri Enstitüsü, İstanbul, Türkiye, 2001.

[15] C.K. Toh, "Vibration analysis in high speed rough and finish milling hardened steel," Journal of Sound and Vibration, vol. 278, no. 1-2, pp. 101-115, November 2004.2 doi: https://doi.org/10.1016/j.jsv.2003.11.012

[16] A. Yardımeden and A. Turan, "Farklı kesme parametreleriyle AISI 1040 çeliğin tornalanmasında oluşan titreşimlerin ve yüzey pürüzlülüğün incelenmesi," DÜMF Mühendislik Degisi, vol. 9, no. 1, pp. 269-278, Nisan 2018.

[17] K. Mori, D. Kono, I. Yamaji and A. Matsubara, "Vibration reduction of machine tool using viscoelastic damper support," Procedia CIRP, vol. 46, pp. 448-451, May 2016. doi: https://doi.org/10.1016/j.procir.2016.03.129

[18] H. Ardıç, "Design and modeling elastomeric vibration isolators using finite element method," Yüksek Lisans Tezi, ODTÜ, Doğa ve Uygulamalı Bilimler Enstitüsü, Ankara, Türkiye, 2013.

[19] K. Mori, D. Kono, I. Yamaji and A. Matsubara, "Modeling of viscoelastic damper for reduction in low frequency residual vibration in machine tools," Precision Engineering, vol. 50, pp. 313-319, October 2017.

doi:

https://doi.org/10.1016/j.precisioneng.2017.06.004

[20] C. Eken, "Üretim tezgahlarında zemin titreşimi ve yalıtımı üzerine bir araştırma," Yüksek Lisans
Tezi, Afyon Kocatepe Üniversitesi, Fen Bilimleri Enstitüsü, Afyonkarahisar, Türkiye, 2017.

[21] E. Karabulut, "Giyotin sac kesme tezgahı zemin titreşim hareketinin araştırılması," Yüksek Lisans Tezi, Afyon Kocatepe Üniversitesi, Fen Bilimleri Enstitüsü, Afyonkarahisar, Türkiye, 2019.

\section{Abdurrahman KARABULUT}

Prof.Dr. Abdurrahman KARABULUT, 1962 yılında Yozgat'ta doğdu. 1983'te Gazi Üniversitesi Teknik Eğitim Fakültesi, Makine Eğitimi, Makine Resim ve Konstrüksiyonu öğretmenliğine girdi. Öğrenciliğin son yılında Gazi Üni. Mühendislik Fak. tarafından yürütülen İzmir'de kurulacak sanayi yerleşim 1s1 fizibilitesi çalışmalarına katıldı. 1987 yılında Anadolu Üniversitesi, Bolvadin Meslek Yüksekokulunda, Öğretim Görevlisi olarak göreve başladı. 1990 yılında yüksek lisansını, 1996 yılında da doktorasını, Gazi Üni. Fen bilimleri enstitüsünde tamamladı. Proje kapsamında İngiltere ve Almanya'da bulundu. 1996 yılında Yardımcı Doçent ünvanını aldı. 2001-2007 ve 2011-2014 arasında AKÜ-Bolvadin Meslek Yüksekokulu Müdürlügünü yaptı. 20 Ocak 2011 'de Doçent, 2016 'da Prof. oldu. Şu anda Afyon Kocatepe Üniversitesi Teknoloji Fakültesi Makine Mühendisliği bölümünde Öğretim Üyesi olarak çalışmaktadır.

\section{Ahmet KÖKEN}

1981 Afyonkarahisar doğumlu olan Ahmet KÖKEN, 2001 yılında Dumlupınar Üniversitesi Simav Teknik Eğitim Fakültesi Makine Eğitimi bölümünden mezun oldu. 2003 yllında mezun olduğu bölümde Öğretim Görevlisi olarak göreve başladı. Dumlupınar Üniversitesi Fen Bilimleri Enstitüsünde 2005 y1lında Yüksek Lisans eğitimini tamamladı. 2017 yılında Afyon Kocatepe Üniversitesi Fen Bilimleri Enstitüsü Makine Mühendisliği Anabilim Dalında doktora eğitimine başladı. Şuan Dumlupınar Üniversitesi Kütahya Teknik Bilimler MYO Öğretim Görevlisi olarak çalışmaktadır. Kompozit malzemeler, titreşim konularında çalışmaları olan Ahmet KÖKEN, evli ve 2 çocuk sahibidir. 